\title{
AVALIAÇÃO DA QUALIDADE DE BANANA PASSA ELABORADA A PARTIR DE SEIS CULTIVARES
}

\author{
Renata Vieira da MOTA
}

\section{RESUMO}

Banana passa foi produzida a partir dos cultivares marmelo, ouro, maçã, nanica, prata e YB $42-03$ por secagem em estufa com circulação forçada de ar, após imersão em solução antioxidante à base de ácido cítrico e ascórbico. Foram utilizados frutos maduros de cinco cultivares facilmente encontrados no comércio local e um cultivar em implantação resistente a Sigatoka Negra (YB 4203). A imersão em solução antioxidante não alterou a composição físico-química dos frutos nem a sua curva de secagem. Os produtos elaborados a partir dos diferentes cultivares apresentaram características próprias de tamanho, cor, acidez, pH e teor de açúcares redutores e não redutores. Este trabalho retrata a viabilidade de elaborar um produto de qualidade, padronizado, com uso de técnicas de fácil aplicação, aproveitando as características naturais da fruta para diferenciar o produto final.

Palavras-chave: Musa spp.; cultivares; desidratação; antioxidante; qualidade.

\section{SUMMARY}

EVALUATION OF THE QUALITY OF DRIED BANANAS PREPARED FROM SIX VARIETIES. Bananas of six different varieties, marmelo, ouro, maçã, nanica, prata and YB 42-03 were dried in an upward air-circulated drier after pre-treatment in antioxidant solution prepared with citric and ascorbic acids. Ripe bananas of five varieties usually found in the local market and one variety resistant to Sigatoka Negra disease (YB 42-03) were tested. Control fruits compared to those completely submerged under the antioxidant solution had similar physico-chemical composition and drying curves. The dried products showed peculiar characteristics of size, color, titrable acidity, $\mathrm{pH}$ and reducing and non reducing sugars. This work shows that it is possible to prepare a standard quality product based on know-how easy to be applied and to make good use of natural characteristics of the fruits to obtain final products with distinct quality.

Keywords: Musa spp.; cultivars; dehydration; antioxidant; quality.

\section{1 - INTRODUÇÃO}

O Brasil ocupa a $3^{a}$ posição entre os países com maior produção de banana, na ordem de 6,5 milhões de toneladas no ano de 2003. A maior parte da produção $(18,1 \%)$ está concentrada no estado de São Paulo, seguida de Bahia (11,7\%), Pará (10,7\%), Santa Catarina $(9,5 \%)$ e Minas Gerais (8,4\%) [9]. De acordo com SILVA [10], somente os bananais do litoral sul do estado de São Paulo contribuem para a exportação. As plantações existentes no planalto paulista e nos estados do Ceará, Goiás, Minas Gerais, Espírito Santo, Rio de Janeiro e Pernambuco abastecem quase que somente o mercado interno.

Diante da grande oferta de um produto perecivel, sujeito a flutuações de preços, a implantação de unidades industriais nas regiões produtoras é uma prática necessária e viável para o aproveitamento dos excedentes de produção, com geração de renda, empregos e redução de perdas. Diversos são os produtos que podem ser obtidos

Recebido para publicação em 26/01/2005. Aceito para publicação em 11/08/2005(001475).

Estação Experimental de Caldas - EPAMIG. Endereço: Av. Santa Cruz, 500. Caixa Postal: 33. CEP: 37780-000, Caldas-MG. E-mail: renata@epamigcaldas.gov.br

A quem a correspondência deve ser enviada. da banana: polpa ou purê, néctar, fruta em calda, produtos desidratados (banana liofilizada, flocos e fruta na forma de passa) e doces diversos, incluindo geléias e doce de massa (bananada).

A desidratação é uma alternativa bastante conhecida para conservação de frutos. É um processo de fácil aplicação que, além de prolongar a vida-de-prateleira, diminui o peso do produto para o transporte e o espaço necessário para o armazenamento [2].

A banana seca ou banana passa apresenta elevado teor de açúcares. Pode ser classificada entre os produtos de alto valor alimentício, facilmente assimilável. Seu valor energético é da ordem de $318 \mathrm{cal} / 100 \mathrm{~g}$, sendo que $125 \mathrm{~g}$ por dia bastariam para cobrir um quarto das necessidades alimentícias de um menino de 10 anos, em valor energético, glicídeos, proteínas de origem vegetal, potássio, ferro e magnésio, e um oitavo das necessidades em fósforo, cloro, zinco e vitamina C [13].

Estudo de mercado realizado por LIRA et al. [6] indicou que a maior parte dos consumidores (53\%) preferem a banana passa pura, $23 \%$ em bolos, $10 \%$ com cobertura de chocolate e $33 \%$ com outras preparações, sendo que muitos optaram por mais de uma forma de consumo. $\mathrm{O}$ produto apresentou grande aceitabilidade na faixa etária do estudo (provadores acima de 25 anos), sendo o sabor, o atributo de qualidade mais apreciado. Apesar de apresentar um elevado índice de aceitabilidade, o consumo da banana passa ainda é pequeno. Uma provável causa para o baixo consumo é a falta de padrão de qualidade dos produtos encontrados no mercado.

Nos últimos anos, técnicas como pré-desidratação 
osmótica [12], sulfuração e imersão em solução antioxidante [13] têm sido indicadas para melhorar a qualidade dos produtos desidratados, normalmente preparados a partir dos cultivares nanica e prata. Entretanto, os cultivares de banana apresentam diferenças acentuadas na composição em carboidratos [7], fator que pode influenciar na qualidade do produto final.

Desta forma, levando em conta a grande disponibilidade de diferentes cultivares de banana nas regiões produtoras, este trabalho teve como objetivo avaliar a qualidade do produto desidratado a partir de seis cultivares de bananas, cinco facilmente encontrados no comércio e um cultivar em fase de implantação resistente a Sigatoka Negra, submetidos ao tratamento de imersão em solução antioxidante.

\section{2 - MATERIAL E MÉTODOS}

Foram utilizados frutos maduros (casca amarela com pintas pretas) dos cultivares marmelo (ou figo), ouro, maçã, nanica e prata, obtidos na feira livre do município de Poços de Caldas (MG) e do cultivar YB 42-03 (híbrido de Yangambi, banana tipo maçã resistente a Sigatoka Negra), fornecido pelo Centro Tecnológico do Sul de Minas (EPAMIG/CTSM) em Lavras (MG).

Os frutos foram lavados em água clorada $(50 \mathrm{ppm}$ cloro livre), descascados e imersos em solução antioxidante contendo $4 \%$ de ácido cítrico e $1 \%$ de ácido ascórbico [13].

Em seguida foram drenados, colocados em bandejas e levados a estufa com circulação de ar a $65^{\circ} \mathrm{C}$ até atingir umidade final de $22 \%$. O final da secagem foi estimado pelo peso seco de produto na bandeja segundo a fórmula [1]:

$\mathrm{Pf}=\mathrm{Pi}(100-\mathrm{Ui}) /(100-\mathrm{Uf})$,

onde:

$\mathrm{Pi}=$ Peso $(\mathrm{kg})$ inicial de bananas de uma bandeja;

$\mathrm{Ui}=$ umidade inicial dos frutos;

$\mathrm{Uf}=$ umidade final desejada para o produto $(22 \%)$;

$\mathrm{Pf}=$ peso $(\mathrm{kg})$ final da banana seca.

Os frutos foram pesados periodicamente durante o período de desidratação para o levantamento das curvas de secagem e a estufa permaneceu desligada durante a noite (aproximadamente 9 horas). Completado o período de secagem, os frutos foram embalados em papel celofane amarelo e mantidos a temperatura ambiente.
A banana passa foi avaliada quanto ao aspecto visual e a composição físico-química pela determinação da umidade, $\mathrm{pH}$, acidez total titulável, sólidos solúveis totais ( $\left.{ }^{\circ} \mathrm{Brix}\right)$ [5], carboidratos totais [3], açúcares redutores e não redutores $[8,11]$. Todos os tratamentos foram realizados em triplicata. Para a análise estatística foi utilizado o Programa ESTAT (V.2.0) [4].

\section{3 - RESULTADOS E DISCUSSÃO}

A imersão em solução antioxidante por um tempo mínimo de 5 minutos impede o escurecimento dos frutos, resultando em um produto final de coloração clara e homogênea.

Estudo preliminar com o cultivar prata indicou que o tratamento com solução antioxidante alterou de forma significativa apenas os teores de acidez total titulável e $\mathrm{pH}$ (Tabela 1), não exercendo influência sobre a curva de secagem (Figura 1).

O uso da solução antioxidante à base de ácidos naturais da fruta em substituição ao anidrido sulfuroso (sulfitação ou sulfuração), normalmente recomendado nos processos industriais [13], elimina o risco de resíduo de $\mathrm{SO}_{2}$ no produto final, garante a elaboração de um produto natural e com boas características visuais.

Em todos os cultivares avaliados, a imersão em solução antioxidante foi responsável por um acréscimo em peso do fruto não superior a $1 \%$, não alterando de forma significativa o teor de umidade inicial dos frutos.

Os cultivares apresentaram curvas diferentes de perda de umidade, com as menores taxas de perda apresentadas pelos cultivares nanica e prata, que são os mais utilizados para a desidratação. O cultivar marmelo apresentou a maior taxa de desidratação, seguido dos cultivares ouro, YB 42-03 e maçã, o que resultou em menor tempo de secagem dos frutos (Figura 2).

Observaram-se diferenças significativas nos teores de umidade final, acidez e $\mathrm{pH}$. Os cultivares ouro e YB 42-03 destacaram-se quanto ao teor de açúcares redutores (Tabela 2).

A relação ${ }^{\circ} \mathrm{Brix} /$ acidez (ratio) variou de 30 a 50, com o menor valor obtido para o cultivar marmelo $(30,4)$ e o maior para o cultivar nanica $(48,7)$. A relação açúcares redutores / não redutores obtida para a maioria dos cultivares foi na faixa de 27:1, com exceção dos cultivares ouro e YB 42-03 que apresentaram teores mais elevados de açúcares não redutores (relação de 5,8:1 e 1,4:1, respectiva-

TABELA 1 - Características físico-químicas dos frutos in natura do cultivar prata submetidos ou não à imersão em solução antioxidante

\begin{tabular}{|c|c|c|c|c|c|c|c|}
\hline Tratamento & $\begin{array}{c}\text { Umidade } \\
(\% \text { b.u })\end{array}$ & $\begin{array}{c}\text { SST } \\
\left({ }^{\circ} \text { Brix }\right)\end{array}$ & $\begin{array}{c}\text { Acidez } \\
\text { (\% ácido } \\
\text { málico) }\end{array}$ & $\mathrm{pH}$ & $\begin{array}{c}\text { Carboidratos } \\
(\%)\end{array}$ & $\begin{array}{c}\text { Açúcares } \\
\text { Redutores } \\
(\%)\end{array}$ & $\begin{array}{c}\text { Açúcares Não } \\
\text { Redutores } \\
(\%)\end{array}$ \\
\hline Controle & $\begin{array}{c}74,450 \pm \\
0,289 \mathrm{~A}\end{array}$ & $\begin{array}{c}18,532 \pm \\
0,221 \mathrm{~A}\end{array}$ & $\begin{array}{c}0,369 \pm 0,007 \\
B\end{array}$ & $\begin{array}{l}4,777 \pm \\
0,015 \mathrm{~A}\end{array}$ & $\begin{array}{c}15,109 \pm 1,333 \\
\mathrm{~A}\end{array}$ & $\begin{array}{c}12,277 \pm 0,619 \\
\text { A }\end{array}$ & $8,797 \pm 1,330 \mathrm{~A}$ \\
\hline $\begin{array}{l}\text { Solução } \\
\text { Antioxidante }\end{array}$ & $\begin{array}{c}75,130 \pm \\
0,141 \mathrm{~A}\end{array}$ & $\begin{array}{c}18,378 \pm \\
0,808 \mathrm{~A}\end{array}$ & $\begin{array}{c}0,518 \pm 0,008 \\
\mathrm{~A}\end{array}$ & $\begin{array}{l}4,527 \pm \\
0,006 \mathrm{~B}\end{array}$ & $\begin{array}{c}14,659 \pm 0,478 \\
\mathrm{~A}\end{array}$ & $\begin{array}{c}13,202 \pm 0,726 \\
\mathrm{~A}\end{array}$ & $7,393 \pm 1,686 \mathrm{~A}$ \\
\hline
\end{tabular}




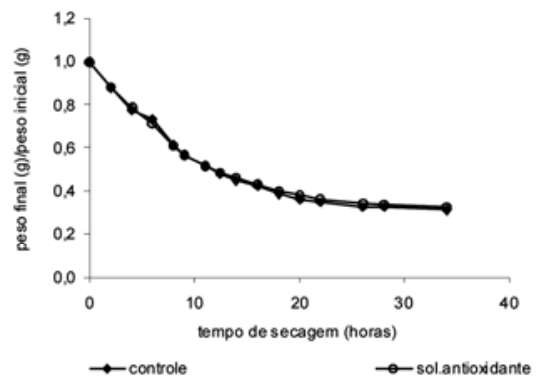

FIGURA 1 - Curva de secagem de banana cultivar prata tratada ou não com solução antioxidante

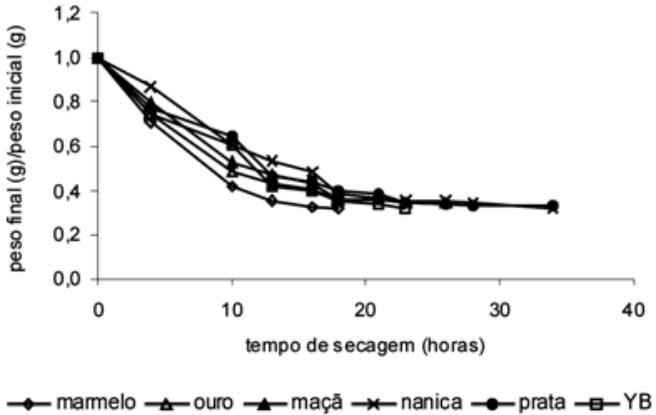

FIGURA 2 - Curva de secagem de seis cultivares de bananas

TABELA 2 - Composição físico-química de banana passa obtida a partir de seis cultivares

\begin{tabular}{|c|c|c|c|c|c|c|c|c|}
\hline Cultivar & $\begin{array}{c}\text { Umidade } \\
\text { (\% b.u) }\end{array}$ & $\begin{array}{c}\text { SST } \\
\left({ }^{\circ} \text { Brix }\right)\end{array}$ & $\begin{array}{c}\text { Acidez } \\
\text { (\% ácido } \\
\text { málico) }\end{array}$ & $\mathrm{pH}$ & $\begin{array}{c}\text { Carboidratos } \\
(\%)\end{array}$ & $\begin{array}{c}\text { Açúcares } \\
\text { Redutores } \\
(\mathrm{mg} / \mathrm{g})\end{array}$ & $\begin{array}{c}\text { Açúcares } \\
\text { Totais } \\
(\mathrm{mg} / \mathrm{g})\end{array}$ & $\begin{array}{c}\text { Açúcares Não } \\
\text { Redutores } \\
(\mathrm{mg} / \mathrm{g})^{*}\end{array}$ \\
\hline Marmelo & $\begin{array}{l}25,290 \pm \\
0,326 \mathrm{AB}\end{array}$ & $\begin{array}{c}65,270 \pm \\
1,754 \mathrm{~A}\end{array}$ & $\begin{array}{l}2,148 \pm \\
0,078 \mathrm{~A}\end{array}$ & $\begin{array}{c}4,433 \pm 0,012 \\
D\end{array}$ & $45,322 \pm 2,168 \mathrm{~A}$ & $\begin{array}{c}534,234 \pm \\
16,669 \mathrm{~A}\end{array}$ & $\begin{array}{c}553,313 \pm \\
20,258 \mathrm{~A}\end{array}$ & 19,079 \\
\hline Ouro & $\begin{array}{l}21,450 \pm \\
0,454 \mathrm{C}\end{array}$ & $\begin{array}{c}67,234 \pm \\
1,131 \mathrm{~A}\end{array}$ & $\begin{array}{l}1,785 \pm \\
0,046 \mathrm{C}\end{array}$ & $\begin{array}{c}4,717 \pm 0,015 \\
B\end{array}$ & $45,126 \pm 1,516 \mathrm{~A}$ & $\begin{array}{c}455,228 \pm \\
12,773 \mathrm{~B}\end{array}$ & $\begin{array}{c}533,074 \pm \\
18,823 \mathrm{~A}\end{array}$ & 77,846 \\
\hline Maçã & $\begin{array}{c}26,090 \pm \\
0,204 \mathrm{~A}\end{array}$ & $\begin{array}{c}67,614 \pm \\
1,587 \mathrm{~A}\end{array}$ & $\begin{array}{l}1,970 \pm \\
0,066 \mathrm{~B}\end{array}$ & $\begin{array}{c}4,353 \pm 0,012 \\
E\end{array}$ & $47,182 \pm 0,658 \mathrm{~A}$ & $\begin{array}{c}514,203 \pm \\
2,680 \mathrm{~A}\end{array}$ & $\begin{array}{c}531,774 \pm \\
15,798 \mathrm{~A}\end{array}$ & 17,571 \\
\hline Nanica & $\begin{array}{c}24,350 \pm \\
0,606 \mathrm{~B}\end{array}$ & $\begin{array}{c}66,728 \pm \\
1,280 \mathrm{~A}\end{array}$ & $\begin{array}{l}1,370 \pm \\
0,063 \mathrm{D}\end{array}$ & $4,897 \pm 0,012$ & $43,455 \pm 0,212 \mathrm{~A}$ & $\begin{array}{c}503,560 \pm \\
16,657 \mathrm{~A}\end{array}$ & $\begin{array}{c}520,475 \pm \\
32,623 \mathrm{~A}\end{array}$ & 16,915 \\
\hline Prata & $\begin{array}{c}23,890 \pm \\
0,933 \mathrm{~B}\end{array}$ & $\begin{array}{c}1,280 \mathrm{~A} \\
66,955 \pm \\
1,371 \mathrm{~A}\end{array}$ & $\begin{array}{l}1,702 \pm \\
0,004 \mathrm{C}\end{array}$ & $\begin{array}{c}4,627 \pm 0,012 \\
C\end{array}$ & $45,476 \pm 2,600 \mathrm{~A}$ & $\begin{array}{l}505,625 \pm \\
32,175 \mathrm{~A}\end{array}$ & $\begin{array}{c}529,417 \pm \\
4,114 \mathrm{~A}\end{array}$ & 23,792 \\
\hline $\begin{array}{l}\text { YB } \\
42-03\end{array}$ & $\begin{array}{l}24,950 \pm \\
0,224 \mathrm{AB}\end{array}$ & $\begin{array}{c}67,635 \pm \\
0,347 \mathrm{~A}\end{array}$ & $\begin{array}{l}1,460 \pm \\
0,004 \mathrm{D}\end{array}$ & $\begin{array}{c}4,733 \pm 0,012 \\
B\end{array}$ & $45,992 \pm 2,182 \mathrm{~A}$ & $\begin{array}{c}310,230 \pm \\
9,173 \mathrm{C}\end{array}$ & $\begin{array}{c}536,510 \pm \\
19,015 \mathrm{~A}\end{array}$ & 226,280 \\
\hline
\end{tabular}

mente). As diferenças apresentadas na composição química dos frutos conferem aos produtos obtidos dos diferentes cultivares características próprias de sabor.

Além das mudanças físico-químicas apresentadas na Tabela 2, os produtos elaborados a partir dos diferentes cultivares apresentaram coloração diferenciada. A intensidade de cor passou de amarelo claro para o cultivar marmelo até uma coloração bronzeada, nos cultivares ouro, nanica e maçã. Os cultivares prata e YB 42-03 apresentaram coloração intermediária.

O cultivar marmelo, por exemplo, por apresentar coloração mais clara e sabor doce menos acentuado, pode ser explorado no preparo da fruta desidratada com cobertura de chocolate. O produto final apresentaria um contraste de cor e sabor mais interessante do que o obtido com o cultivar nanica.

A desidratação por secagem em estufa, após tratamento dos frutos em solução antioxidante, permite a elaboração de produtos com coloração uniforme e padronização. Além disso, o produto elaborado mantém o ratio característico da fruta, como pode ser observado nos dados das Tabelas 1 e 2 para o cultivar prata. O fruto in natura tratado com solução antioxidante apresentou ratio de 35,5 (Tabela 1) e o fruto desidratado apresentou ratio de 39,3 (Tabela 2).

O emprego do pré-tratamento osmótico, apesar de acelerar a desidratação [12], é um processo que reduz a acidez natural da fruta e incorpora certa quantidade de sólidos ao produto, com aumento do seu valor calórico e perda do sabor característico da fruta determinado pelo balanço entre açúcares e ácidos.

No caso da banana, que apresenta naturalmente elevado conteúdo de açúcares e, portanto, boa conservação mesmo a temperatura ambiente, o pré-tratamento com solução antioxidante é mais vantajoso, pois além de manter as características naturais da fruta, é um processo mais barato e de fácil aplicação.

\section{4 - CONCLUSÕES}

- O emprego do pré-tratamento com solução antioxidante resulta em um produto desidratado padronizado que mantém as características naturais da fruta, além de ser um processo de fácil aplicação, rápido e relativamente barato levando-se em conta o custo total do processo de desidratação.

- Os cultivares mais utilizados no preparo da banana passa (prata e nanica) são os que apresentam maior tempo de desidratação. O emprego de cultivares como marmelo, ouro e maçã, facilmente disponíveis no mercado, permite a elaboração dos produtos em menor tempo, reduzindo o custo de operação.

- A grande variabilidade de cultivares existentes con- 
fere aos produtos desidratados características específicas de tamanho, cor e sabor, diferencial que deve ser melhor trabalhado perante o consumidor.

\section{5 - REFERÊNCIAS BIBLIOGRÁFICAS}

[1] AGUIRRE, J.M. Produção de tomate parcialmente desidratado e marinado. Campinas: ITAL, 2004. 24p. (Material Técnico Curso de Desidratação de Frutas e Hortaliças ITAL/FRUTHOTEC, Campinas de 26 a 28 de maio de 2004).

[2] AGUIRRE, J.M., GASPARINO FILHO, J. Desidratação de Frutas e Hortaliças. Campinas: ITAL, 2002. 205p. (Manual Técnico).

[3] DUBOIS, M., GILES, K.A., HAMILTON, J.K., REBERS, P.A., SMITH, F. Colorimetric method for determination of sugars and related substances. Anal. Chem., v.28, p.350, 1956.

[4] ESTAT - Sistema para análises estatísticas. Pólo computacional/Departamento de Ciências Exatas. UNESP-FCAV - Campus de Jaboticabal. V.2.0.

[5] INSTITUTO ADOLFO LUTZ. Normas Analiticas do Instituto Adolfo Lutz. Métodos químicos e físicos para análise de alimentos, v.1, 3.ed. São Paulo: Inst. Adolfo Lutz, 1985. 533p.

[6] LIRA, R.A., FERNANDES, N.S., RABELLO, A., ZUNIGA, A.D.G. Estudo da aceitabilidade e freqüência de consumo de banana passa. (resumo). Disponivel em http://www.uft.edu.br/jornada. Acesso em: 30 nov. 2004.

[7] MOTA, R.V., LAJOLO, F.M., CORDENUNSI, B.R. Composição em carboidratos de alguns cultivares de banana (Musa spp) durante o amadurecimento. Ciênc. Tecnol. Aliment., Campinas, v. 17, n.2, p.94-97, 1997.

[8] NELSON, N.A. Photometric adaptation of the Somogy method for the determination of glucose. J. Biol. Chem., Baltimore, n.153, p.375-380, 1944.
[9] SECRETARIA DE POLÍticA AGRÍCOLA / MAPA Produtos selecionados da agropecuária. In: Agricultura Brasileira em Números. Anuário 2003. Cap. 3. Estatísticas.

Disponivel em http://www.agricultura.gov.br. Acesso em: 30 nov. 2004.

[10] SILVA, E.M.F. (coord.) Estudos sobre o mercado de frutas. São Paulo: FIPE, 1999. 373p. Disponível em http://www.agricultura.gov.br. Acesso em: 25 nov. 2004.

[11] SOMOGY, M. Determination of blood sugar. J. Biol. Chem., Baltimore, n.160, p. 69-73, 1945.

[12] SOUSA, P.H.M., MAIA, G.A., SOUZA FILHO, M.S.M., FIGUEIREDO, R.W., NASSU, R.T., SOUZA NETO, M.A. Influência da concentração e da proporção fruto:xarope na desidratação osmótica de bananas processadas. Ciênc Tecnol. Aliment., Campinas, v.23 (supl.), p. 126130, 2003

[13] TRAVAGLINI, D.A., AGUIRRE, J.M., SILVEIRA, E.T.F. Desidratação de Frutas. In: AGUIRRE, J.M., GASPARINO FILHO, J. Desidratação de Frutas e Hortaliças. Campinas: ITAL, 2002. (Manual Técnico). Cap. 3, p.3-1 a 3-19.

\section{6 - AGRADECIMENTOS}

Ao CNPq pela bolsa de recém-doutor.

Aos funcionários e pesquisadores da Estação Experimental de Caldas (EPAMIG/FECD), que não mediram esforços em proporcionar os meios necessários para a elaboração deste trabalho.

Ao pesquisador Lair Victor Pereira, do Centro Tecnológico do Sul de Minas (EPAMIG/CTSM), por ter enviado o material resistente a Sigatoka Negra.

Às empresas Plury Química e Doce Aroma pelo fornecimento dos ácidos cítrico e ascórbico utilizados neste trabalho. 